Editorial

\title{
Exploring and Modeling the Magma-Hydrothermal Regime
}

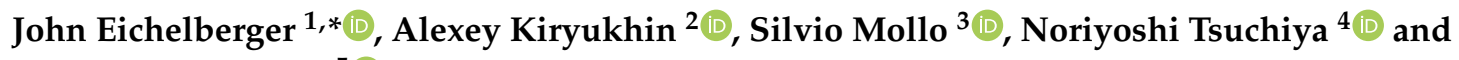 \\ Marlène Villeneuve 5 (D) \\ 1 International Arctic Research Center, University of Alaska Fairbanks, Fairbanks, AK 99775, USA \\ 2 Institute of Volcanology and Seismology, FEB RAS, 683006 Petropavlovsk-Kamchatsky, Russia; \\ avkiryukhin2@mail.ru \\ 3 Department of Earth Sciences, Sapienza University of Rome, 00185 Roma, Italy; silvio.mollo@uniroma1.it \\ 4 Graduate School of Environmental Studies, Geomaterial and Energy Lab., Tohoku University, \\ Sendai 980-8579, Japan; noriyoshi.tsuchiya.e6@tohoku.ac.jp \\ 5 Montanu Niversität Leoben, Erzherzog Johann-Straße 3, A-8700 Leoben, Austria; \\ marlene.villeneuve@unileoben.ac.at \\ * Correspondence: jceichelberger@alaska.edu; Tel.: +1-907-888-0204
}

Received: 16 June 2020; Accepted: 16 June 2020; Published: 18 June 2020

\begin{abstract}
This special issue comprises 12 papers from authors in 10 countries with new insights on the close coupling between magma as an energy and fluid source with hydrothermal systems as a primary control of magmatic behavior. Data and interpretation are provided on the rise of magma through a hydrothermal system, the relative timing of magmatic and hydrothermal events, the temporal evolution of supercritical aqueous fluids associated with ore formation, the magmatic and meteoric contributions of water to the systems, the big picture for the highly active Krafla Caldera, Iceland, as well as the implications of results from drilling at Krafla concerning the magma-hydrothermal boundary. Some of the more provocative concepts are that magma can intrude a hydrothermal system silently, that coplanar and coeval seismic events signal "magma fracking" beneath active volcanoes, that intrusive accumulations may far outlast volcanism, that arid climate favors formation of large magma chambers, and that even relatively dry rhyolite magma can convect rapidly and so lack a crystallizing mush roof. A shared theme is that hydrothermal and magmatic reservoirs need to be treated as a single system.
\end{abstract}

Keywords: magma-hydrothermal; geothermal energy; volcanology; magma convection; heat transport; gas and fluid geochemistry; phreatic eruption; volcano monitoring; geophysical imaging; drilling

\section{Introduction}

The purpose of this special issue is to report new results bearing on the close connection between magma and hydrothermal reservoirs. The editors' intent is igniting broader discussion and a more holistic view wherein magma and hydrothermal regimes are viewed as an integrated system of mass and heat transport from Earth's mantle to the upper crust, surface, and atmosphere. A challenge is that people use different kinds of data to understand limited portions and/or processes of these huge systems, in parts of which the fluid phase is silicate melt and in another, cooler part, aqueous liquid. Throughout there can exist a water-dominated vapor phase. Geologists have long studied the dead exposed remnants of magma-hydrothermal systems. Microanalytical techniques, including chemistry of fluid inclusions and radiometric dating of individual minerals and zones within them have produced great advances in understanding their evolution. Volcanologists are largely surface-bound, and rely 
on remote geophysical and geochemical sensing from surface networks, space, or the atmosphere between, as well as analyses of rock and gas samples from eruptions. As an example of resulting differences, those who study volcanism are more convinced that magmas convect than those who study cold exposed igneous intrusion. This may be just a matter of stage. Exposed plutons are the end product of magma-hydrothermal activity whereas volcanoes erupt only magmas that are in a relatively early stage of crystallization and hence are mobile.

The greater disconnect is between magmatic and geothermal investigations. The former is usually undertaken for basic science or for mitigating the disaster risk from eruptions, the latter for the economic incentive of electric power and/or heat production. The data acquired and the models for interpreting data pertain on the one hand to mass and heat transport in a multi-phase suspension dominated by silicate melt and on the other to porous flow of aqueous fluid through a solid medium of variable physical properties. Given the economic incentive, geothermal data in the private sector are often not as accessible as data from magmatic systems, typically produced by academic or government scientists. However, accidental geothermal drilling encounters with magma are bringing these communities together. Magma is no longer an abstract concept to geothermalists, and those who theorize about magma must deal with the subsolidus complexities above it and accept the realities revealed by samples of magma quenched at depth.

Until recent drilling encounters with magma, a magma chamber was essentially a black box to scientists. Mass and heat output could reasonably be inferred by observations within hydrothermal systems or at the surface, plus volume measurements of volcanic deposits. Input from below to the box is more difficult to estimate, though $\mathrm{CO}_{2}$ emission rate and surface deformation are helpful.

It is not too extreme to assert that hydrothermal circulation largely controls what happens inside the magma box [1,2]. This is because advective heat transport in the hydrothermal reservoir is orders of magnitude faster than simple conduction without hydrothermal circulation. The rate of release of thermal energy from the magma is controlled by such parameters as porosity, permeability, and water supply in the overlying rock.

\section{Phreatomagmatic Activity}

We can begin at the surface where the clearest evidence of direct magma-hydrothermal interaction are steam-rich explosions, a result of which is depicted on the volume cover at Krafla Caldera, Iceland. In 1976, phreatic activity and a seismic crisis at Soufriere de Guadeloupe, French West Indies attracted world attention when a volcanologist said that the volcano would explode like an atomic bomb. About 75,000 people were evacuated from the volcano's vicinity, an especially great misfortune for those who were farmers. No such magmatic eruption followed, and this experience demonstrated two things: (1) disaster mitigation efforts can do more harm than good; and (2) careful monitoring and understanding of such restless systems are required. Tamburello et al. [3] report a state-of-the-art analysis of current increased restlessness at Soufriere. They provide data and interpretation that was not possible in 1976 and argue that the current activity is due to magma at 6-7 km depth rather than rise of new magma into the summit dome. Probably the failed eruption of Soufriere in 1976 influenced many volcanologists to think that $>2$ months of phreatic activity at Mount St Helens, USA, in 1980 would fizzle out as well. Instead, a catastrophic magmatic eruption followed.

However, even phreatic eruptions, though generally smaller than magmatic ones, can be deadly. Fumarolic manifestations attract tourists and explosions are notoriously hard the forecast. In Japan, the eruption of Mount Ontake on 27 September 2014 killed 63 climbers. Tajima et al. [4] were fortunate to be able to obtain a time-series of fluid chemistry and temperature data leading up to a magmatic hydrothermal eruption of Ebinokogen Ioyama on 18 April 2018. There were no injuries, but as with Mount Ontake the summit fumaroles of Ebinokogen Ioyama attract hikers. They found that the hydrothermal fluids prior to eruption contained both magmatic and meteoric components, as well as evidence that the magmatic input required about 2 months to arrive in the shallow system. It appears 
that an increase in gas release from the magma at depth provided a kick that induced top-down flashing to steam in multiple small shallow hydrothermal reservoirs, producing the explosion.

The most recent magma-hydrothermal event that made world news was the explosion at a popular tourist destination, Wakaari/White Island Volcano, New Zealand on 9 December 2019. Forty-seven tourists and their guides were in the crater at the time of the eruption, of whom 21 died and 26 were injured, most of the latter seriously. Again, there is the deadly combination of a tourist attraction with a high level of baseline fumarolic and seismic activity (Figure 1), so it is difficult to distinguish definite precursory signals. A heightened alert level had been announced.

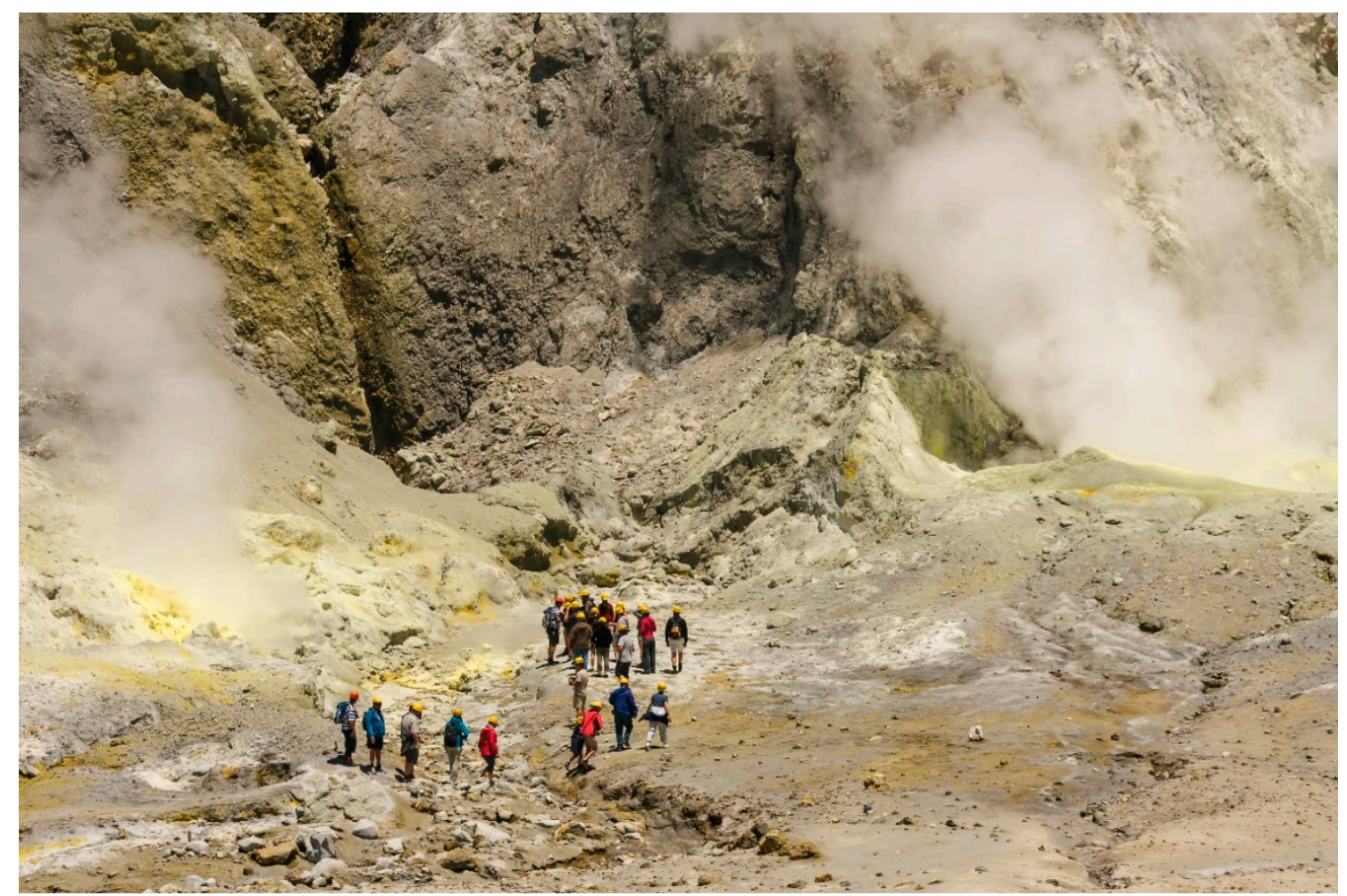

Figure 1. A tour group explores the fumarole field in the crater of Whakaari/White Island Volcano,

New Zealand. Photo credit: Patjo/Shutterstock.com.

White Island Volcano (Whakaari in Te Reo Māori) is a composite, mostly submerged basaltic andesite to dacite volcano characterized by frequent small eruptions and extensive fumarolic activity. Jolly et al. [5] describe how magma rose intact through the hydrothermal system and reached the surface in 2012. The ascent is surmised to have begun after ash venting on 2 September and lava was first observed at the surface in late November, all rather quietly. This is contrary to expectations and to the premonitory seismic events of late 2019. Also remarkable is the gradual increase in frequency of tremor spectral lines during the rise of magma, perhaps due to shortening of the empty portion of the resonating conduit ahead of the magma.

Kennedy et al. [6] report on rock mechanical and geochemical investigations of ballistics from White Island explosions, which they infer to represent the material that normally occupies the upper conduit between eruptions. Cracks and clasts are sealed with alunite and anhydrite. This hydrothermally altered material exhibits highly pressure-dependent permeability in contrast to fresh rocks of similar porosity. They conclude that this interplay between pressure and permeability results in rapidly varying hydrothermal fluid and magmatic gas flow up the conduit.

Not all the surface hydrothermal manifestations of magma at depth are driven by water. Uzon Caldera in Kamchatka, Russia formed at about $40 \mathrm{ka}$. Within it is the Valley of Geysers, a famous tourist attraction. The most recent evidence of magmatic activity was detected by InSAR as $15 \mathrm{~cm}$ 
of uplift during 1999-2003. This deformation may have caused a debris flow in 2007 that dammed a river and drowned many of the geysers. The new magma would have also introduced new $\mathrm{CO}_{2}$ into the hydrothermal system, with the result that some geyser activity switched to sub-boiling $\mathrm{CO}_{2}$ bubble-lift (what water well drillers would call airlift) activity, rather than geysering due to boiling of water. Kiryukhin and Karpov [7] speculate that an abundance of $\mathrm{CO}_{2}$ in the hydrothermal system could have unexpected consequences, such as diatreme formation.

\section{Relationships between Magmatic Processes and Hydrothermal Evolution}

Moving discussion deeper into magma-hydrothermal systems, Kiryukhin et al. [8] used a computer algorithm, Frac Digger, to pick seismic events that are coincident in time and align in a single plane. They interpret these as signaling "magma fracking". They occur in the upper $10 \mathrm{~km}$ of crust beneath the volcano and enhance hydrothermal activity as expressed in temperature and $\mathrm{CO}_{2}$ emission.

Agroli et al. [9] investigated the Erdenet $\mathrm{Cu}$-Mo Deposit, in Mongolia. The ore deposits formed in association with emplacement and cooling of pulses of granodioritic magma. Their emphasis is on the role of the supercritical fluids that were responsible for transport of copper and molybdenum and are also of much current interest as a greatly enhanced geothermal power source. They use a variety of geobarometric and geothermometric techniques, especially Ti-in-quartz geothermometry, coupled with fluid inclusion studies to track the evolution of the system as it cooled. They infer the system began with magma emplacement at about $200 \mathrm{MPa}$ and $750 \mathrm{C}$. Veins with euhedral quartz started to develop with cooling to near the granodiorite solidus and this sealed fractures, resulting in a rise in fluid pressure and precipitation of ores. They make the interesting point that fluid pressure likely switches from lithostatic to hydrostatic as temperature falls below the brittle-ductile transition. The fluid is then sub-critical and only quartz is deposited.

Stearns et al. [10] provide a wealth of geochronological, apparent temperature, and geochemical data from a magma-hydrothermal system in Utah, USA that is exposed through a reconstructed depth range of $>11 \mathrm{~km}$. What volcanologists especially will find notable is that activity spanned more than $10 \mathrm{Ma}$, with volcanism ending midway through this time. Nevertheless, plutons continued to grow incrementally, accompanied by pulses of hydrothermal activity. Although at the conclusion of magmatic activity the intrusive and extrusive portions were comparable in volume, the intrusive volume accumulated much more slowly.

Bartley et al. [11] present both geologic and petrologic evidence that the rise of granitic magmas is an important means of water and heat transport in the crust, an upward flowing supercritical aqueduct. They envision that in general granitic plutons grow incrementally from the top down. Because water is contained primarily in solution in the melt phase, virtually all is released during crystallization, carrying a substantial portion of the magma's thermal energy upward through its older but cogenetic roof and into the suprajacent hydrothermal system, modifying both on the way. Using a novel diagram displaying enthalpy of the system vs. water content of magma, they show that the rise of supercritical magmatic water can remelt previously emplaced granite even though the latter is well below the solidus.

Working in the opposite, descending direction, Glazner [12] presents the provocative idea that climate exerts a strong control on the development of magma bodies. He derives a dimensionless number, $\mathrm{M}$, that shows as a function of volume rate of accretion of incremental intrusions and the difference between heat flow into the base of the plutonic box vs. out through the top, whether a magma body will grow or the plutonic accumulation will remain as separate, mostly solid units. Because heat output is largely controlled by the vigor of hydrothermal circulation and this in turn by water supply, the growth of very large magma chambers may be favored by an arid climate. 


\section{Geophysical and Drilling Insights from the Krafla Magma-Hydrothermal System, Iceland}

Lastly, we come to perhaps the most drilled and geophysically, geochemically, and volcanologically probed magma-hydrothermal system, Krafla Caldera, Iceland. Arnason [13] provides an up-to-date synthesis of our understanding of the Krafla system. This is a must-read for anyone interested in this remarkable volcano growing astride the American-European Plate boundary, by an author who has spent much of his career studying Krafla.

Eichelberger [14] takes lessons from lava lake drilling and new insights, centered on Krafla, from accidental geothermal drilling encounters with silicic magma to further develop the concept of a conductive, magma-hydrothermal boundary (MHB) between magma and the hydrothermal system. MHB can move downward through thermal cracking at the top of MHB or upward by melting at its base. A conclusion, based on drilling-produced evidence of near-liquidus magma in contact with partial melting at the base of MHB, suggests that Krafla's rhyolite body is substantial and convecting. This conflicts with some concepts of magma chambers and much conventional wisdom about Krafla. This and other concepts of magma-hydrothermal systems can be rigorously tested by intentional scientific drilling through hydrothermal systems to magma. Such drilling could also lead to a quantum leap in production geothermal energy (Figure 2) and reliable eruption forecasts.

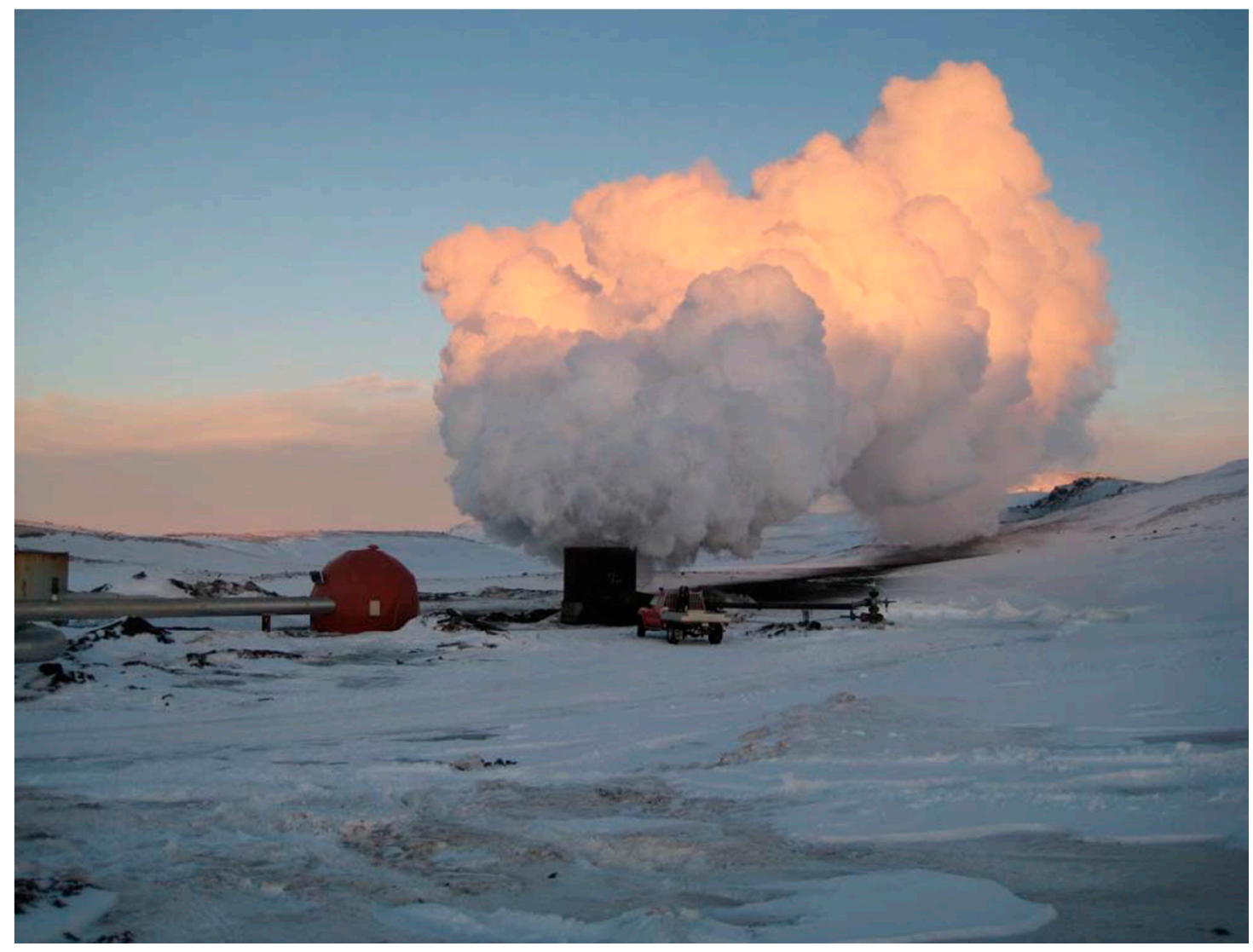

Figure 2. Flow test of Well KJ-36, Krafla Caldera, Iceland on 12 December 2007. Just two super-hot wells such as this near-magma borehole and IDDP-1, which penetrated rhyolite magma [14], could power Landsvirkjun's 60 MWe power plant at Krafla, if the engineering challenges can be overcome. The well slants under Viti Crater (cover photo) and reaches a vertical depth of about $2500 \mathrm{~m}$ approximately $500 \mathrm{~m}$ north of the crater. Photo credit: Ásgrímur Gudmundsson.

\section{Conclusions}

The editors are grateful to the many authors, from ten countries, who contributed to this volume. We hope this will stimulate more investigation, including scientific drilling, and discussion of the 
magma-hydrothermal connection. Much remains to be done to combine and reconcile the insights of volcanologists, igneous petrologists who study plutons, and geothermalists, to understand the magma-hydrothermal regime as a single system.

Funding: This research received no external funding.

Acknowledgments: We thank Richard Li of MDPI/Geosciences for suggesting the magma-hydrothermal theme for a special issue.

Conflicts of Interest: The authors declare no conflict of interest.

\section{References}

1. Carrigan, C.R. Biot number and thermos bottle effect: Implications for magma-chamber convection. Geology 1988, 16, 771-774. [CrossRef]

2. Hawkesworth, C.J.; Blake, S.; Evans, P.; Hughes, R.; Macdonald, R.; Thomas, L.E.; Turner, S.P.; Zellmer, G. Time scales of crystal fractionation in magma chambers-Integrating physical, isotopic and geochemical perspectives. J. Petrol. 2000, 41, 991-1006. [CrossRef]

3. Tamburello, G.; Moune, S.; Allard, P.; Venugopal, S.; Robert, V.; Rosas-Carbajal, M.; Deroussi, S.; Kitou, G.-T.; Didier, T.; Komorowski, J.-C.; et al. Spatio-temporal relationships between fumarolic activity, hydrothermal fluid circulation and geophysical signals at an arc volcano in degassing unrest: La Soufrière of Guadeloupe (French West Indies). Geosciences 2019, 9, 480. [CrossRef]

4. Tajima, Y.; Nakada, S.; Maeno, F.; Huruzono, T.; Takahashi, M.; Inamura, A.; Matsushima, T.; Nagai, M.; Funasaki, J. Shallow magmatic hydrothermal eruption in April 2018 on Ebinokogen Ioyama Volcano in Kirishima Volcano Group, Kyushu, Japan. Geosciences 2020, 10, 183. [CrossRef]

5. Jolly, A.; Caudron, C.; Girona, T.; Christenson, B.; Carniel, R. "Silent" dome emplacement into a wet volcano: Observations from an effusive eruption at White Island (Whakaari), New Zealand in late 2012. Geosciences 2020, 10, 142. [CrossRef]

6. Kennedy, B.M.; Farquhar, A.; Hilderman, R.; Villeneuve, M.C.; Heap, M.J.; Mordensky, S.; Kilgour, G.; Jolly, A.; Christenson, B.; Reuschlé, T. Pressure controlled permeability in a conduit filled with fractured hydrothermal breccia reconstructed from ballistics from Whakaari (White Island), New Zealand. Geosciences 2020, 10, 138. [CrossRef]

7. Kiryukhin, A.V.; Karpov, G. A CO $\mathrm{CO}_{2}$-driven gas lift mechanism in Geyser Cycling (Uzon Caldera, Kamchatka). Geosciences 2020, 10, 180. [CrossRef]

8. Kiryukhin, A.; Chernykh, E.; Polyakov, A.; Solomatin, A. magma fracking beneath active volcanoes based on seismic data and hydrothermal activity observations. Geosciences 2020, 10, 52. [CrossRef]

9. Agroli, G.; Okamoto, A.; Uno, M.; Tsuchiya, N. Transport and evolution of supercritical fluids during the formation of the erdenet cu-mo deposit, Mongolia. Geosciences 2020, 10, 201. [CrossRef]

10. Stearns, M.A.; Bartley, J.M.; Bowman, J.R.; Forster, C.W.; Beno, C.J.; Riddle, D.D.; Callis, S.J.; Udy, N.D. Simultaneous magmatic and hydrothermal regimes in alta-little cottonwood stocks, Utah, USA, Recorded Using Multiphase U-Pb Petrochronology. Geosciences 2020, 10, 129. [CrossRef]

11. Bartley, J.M.; Glazner, A.F.; Stearns, M.A.; Coleman, D.S. The granite aqueduct and autometamorphism of plutons. Geosciences 2020, 10, 136. [CrossRef]

12. Glazner, A.F. Climate and the development of magma chambers. Geosciences 2020, 10, 93. [CrossRef]

13. Árnason, K. New conceptual model for the magma-hydrothermal-tectonic system of krafla, NE Iceland. Geosciences 2020, 10, 34. [CrossRef]

14. Eichelberger, J. Distribution and transport of thermal energy within magma-hydrothermal systems. Geosciences 2020, 10, 212. [CrossRef]

(C) 2020 by the authors. Licensee MDPI, Basel, Switzerland. This article is an open access article distributed under the terms and conditions of the Creative Commons Attribution (CC BY) license (http://creativecommons.org/licenses/by/4.0/). 